\title{
Estudos sobre ciclos e progressão escolar no Brasil: uma revisão
}

\author{
Elba Siqueira de Sá Barretto \\ Universidade de São Paulo e Fundação Carlos Chagas \\ Sandra Zákia Sousa \\ Universidade de São Paulo
}

\section{Resumo}

Este artigo faz uma revisão de estudos publicados sobre ciclos e progressão escolar no país, tomando por base levantamento das publicações acadêmicas sobre o tema, que abrangeu o período de 1980 ao primeiro semestre de 2002, bem como trabalhos mais recentes. A partir dos focos identificados na revisão preliminar do material, realizada no referido levantamento, o texto procura destacar: conclusões provenientes do resgate histórico das experiências de introdução dos ciclos nas redes escolares; dados sobre a abrangência e configuração atual das escolas organizadas em ciclos no país; dimensões enfatizadas, omitidas ou pouco exploradas em ensaios ou em pesquisas sobre os ciclos, tais como a sua fundamentação, implementação e apreciação dos resultados; fontes bibliográficas para o estudo das experiências específicas. Especial atenção é dada aos artigos referentes às reformas promovidas em municípios de capitais que introduziram a organização do ensino em ciclos em contextos inovadores, como São Paulo, Belo Horizonte e Porto Alegre. À guisa de conclusão, as autoras consideram que, embora na literatura examinada haja elementos preciosos para a compreensão do atual estágio em que se encontram as questões pertinentes aos ciclos, as políticas em curso demandam mais investigações que abarquem as dimensões de formulação, implementação e impacto, sendo oportunas não apenas as análises de cunho descritivo e analítico, como também os estudos de caráter propositivo.

\section{Palavras-chave}

Ciclos - Progressão escolar - Democratização da escola - Ensino fundamental.

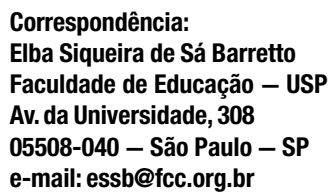




\title{
Studies on school cycles and school progression in Brazil: a survey
}

\author{
Elba Siqueira de Sá Barretto \\ Universidade de São Paulo e Fundação Carlos Chagas \\ Sandra Zákia Sousa \\ Universidade de São Paulo
}

\begin{abstract}
This article is a review of published studies about school cycles and school progression in this country, based on a survey of academic publications on this issue covering the period from 1980 to the first half of 2002, as well as more recent material. From the focal points identified during the preliminary review of the material carried out in the above-mentioned survey the text attempts to highlight: conclusions drawn from the historical recovery of the experiences of introducing cycles in schools; data on the coverage and current configuration of schools organized in cycles in Brazil; dimensions emphasized, omitted or little explored in essays and research on school cycles; bibliographical sources for the study of specific experiences. Special attention is given to recent articles that refer to the reforms carried out in state capital cities, which have introduced the cycle organization within innovative contexts, such as those conducted in São Paulo, Belo Horizonte and Porto Alegre. As a conclusion, the authors consider that, although the literature examined does contain valuable elements to the comprehension of the current stage in which the issues related to school cycles find themselves, the ongoing policies demand further investigation covering the dimensions of formulation, implementation and impact; timely studies are not just those of a descriptive or analytical nature, but also those submitting proposals.
\end{abstract}

\section{Keywords}

School cycles - School progression - School democratization Elementary school.

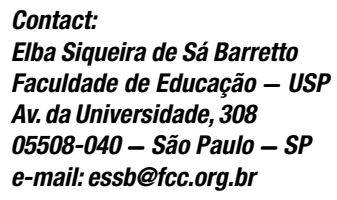


Este artigo faz uma revisão de estudos publicados sobre ciclos e progressão escolar no pais, tomando por base recente levantamento das publicações acadêmicas sobre o tema, realizado por grupo de pesquisa da Faculdade de Educação da USP (Sousa et al. 2003), e trabalhos mais recentes.

0 levantamento refere-se ao periodo de 1980 a meados de 2002 e identifica 96 textos, constituindo um acervo bastante representativo da produção acerca do tema, composto por artigos encontrados em dezesseis das principais revistas da área da educação, livros e capítulos de livros, dissertações de mestrado, teses de doutorado e trabalhos apresentados em encontros científicos.

Os textos foram agrupados segundo o tipo de publicação, a distribuição temporal e as ênfases de análise. A principal fonte de informações científicas sobre os ciclos é constituída por artigos, que representam pouco mais da metade dos textos arrolados, seguida pelas dissertações e teses, que respondem por $23 \%$ dos títulos listados. Quanto ao período de publicação, os estudos que começam a surgir na segunda metade dos anos 1980 e prosseguem até meados dos 1990, abordam questões de implantação e implementação do regime de ciclo nos anos iniciais do ensino fundamental, geralmente chamado ciclo básico ou ciclo de alfabetização. Eles têm, como principal referência, as iniciativas desencadeadas em redes estaduais de ensino. A produção se intensifica a partir do final da década de 1990, período que coincide com a extensão da organização escolar em ciclos para todo o ensino fundamental em muitas redes escolares, municipais e estaduais.

Quanto aos focos de análise privilegiados nos textos, encontram-se: o resgate histórico das experiências de introdução dos ciclos ou progressão continuada no país; os fundamentos, justificativas, potencialidades e implicações das propostas de ciclo e de reorganização do ensino; os dispositivos legais e normativos emanados de diferentes instâncias; as iniciativas de adoção dos ciclos e, por fim, os resultados e ou o impacto das medidas.
Os comentários que faremos a partir de alguns dos focos de análise assinalados nos textos apóiam-se em grande parte na bibliografia indicada pelo estudo referido, mas se valem também de outros materiais, que complementam o primeiro arrolamento e incluem trabalhos publicados até os dias atuais. Eles não esgotam o exame do que já foi produzido sobre tais enfoques, uma vez que este artigo reporta-se a dados parciais de pesquisa mais ampla, ainda em curso. ${ }^{1}$ Possibilitam, no entanto, pontuar o tratamento dado a alguns temas específicos, que têm despertado grande interesse dos estudiosos dos ciclos e dos educadores que com eles trabalham.

\section{Resgate histórico das experiências sob o regime de ciclo no país}

Vários autores têm se ocupado do resgate histórico das experiências de introdução do regime de ciclos como uma forma de organização da escola no país, bem como do debate gerado em torno de seus fundamentos e implicações. Entre as mais recentes e representativas análises sob essa perspectiva estão: Alavarse, 2002; Barretto e Mitrulis, 1999, 2001; Fernandes, 2000; Mainardes, 1998, 2001.

Os ciclos têm a ver com a intenção de regularizar o fluxo de alunos ao longo da escolarização, a fim de assegurar que todos possam cumprir os anos de estudo previstos para o ensino obrigatório, sem interrupções e retenções que inviabilizem a aprendizagem efetiva e uma educação de qualidade. Eles têm recebido denominações diversas, estando, em certa medida, associados a propostas de promoção automática, avanços progressivos, progressão continuada. Vêm também assumindo conotações variadas ao longo dos quase quarenta anos em que ocorreram as muitas inicia-

1. A pesquisa em andamento, coordenada pelas autoras, constitui um Estado do Conhecimento sobre ciclos e progressão continuada. Integram 0 grupo de pesquisa: Andrea Steinvascher, Ocimar M. Alavarse e Paulo H. Arcas, alunos do programa de Pós-Graduação em Educação da FEUSP. 
tivas de introduzi-los nas redes escolares em períodos, lugares e circunstâncias diferentes. Como dizem Barretto e Mitrulis a propósito deles, cada proposta de governo sobre os ciclos "redefiniu o problema à sua maneira, em face da leitura das urgências da época, do ideário pedagógico dominante e do contexto educacional existente" (2001, p. 103).

Nos estudos que procuram recuperar as iniciativas de introdução dos ciclos ao longo do tempo, predominam como fontes de informação, ao lado de ensaios sobre as questões suscitadas por eles, as publicações oficiais das diferentes administrações que os introduziram nas redes de ensino. Por intermédio dessas publicações é possível obter um panorama das iniciativas de introdução dos ciclos no país, identificar as justificativas e os pressupostos em que se baseiam, e, por vezes, ter uma idéia mais clara de seu delineamento e implementação. Se bem que preciosas, as informações provenientes dos órgãos gestores das redes de ensino vêm, inevitavelmente, carregadas da intenção de legitimação das políticas propostas. Estudos que captem diferentes olhares sobre as ações desencadeadas e sejam capazes de apreciar as medidas mediante outras lógicas que não a de seus promotores, têm se multiplicado mais recentemente; não obstante, a grande maioria das experiências de ciclo em curso no país não passou ainda por um crivo acadêmico de análise.

$\mathrm{Na}$ retrospectiva histórica mais abrangente feita sobre o tema, Barretto e Mitrulis registram as vivas discussões sobre promoção automática nos anos 1950, suscitadas pelos elevados índices de retenção na escola primária brasileira; as experiências de implementação de ciclos levadas a cabo em diferentes estados nas décadas de 1960 e 1970; a adoção dos ciclos de alfabetização por vários governos estaduais nos anos 1980; a criação dos ciclos de formação abrangendo o ensino fundamental completo nas propostas político pedagógicas autodenominadas radicais nos anos 1990; a introdução do regime de ciclos e progressão continuada em algumas grandes redes esta- duais na virada do século. Pontuam a mudança de ênfases sobre o tema na legislação nacional e na política, que passa da consideração da medida como passível de acompanhamento e controle experimental na primeira LDB, para entendê-la como uma forma de organização da escola na legislação atual, sinalizada como alternativa a ser adotada mais amplamente pelas redes de ensino do país. Rastreiam ainda a expansão do regime de ciclos nas redes escolares dos municípios e estados brasileiros, mediante o exame dos dados do censo escolar de 2000, e discutem os pontos de vista de diferentes atores e as controvérsias suscitadas pelos ciclos.

Vale reter algumas de suas considerações finais. A despeito de tantas décadas passadas e das muitas mudanças na sociedade e no contexto mundial, assim como nos próprios sistemas educativos, permanecem constantes as justificativas adotadas para a adoção dos ciclos e seu substrato comum. Por sua vez, embora as experiências brasileiras sejam muito diversas e numerosas, muitas delas têm sofrido interrupção abrupta; além disso, um número grande de iniciativas de introdução dos ciclos é recente. Outro dado que merece ser destacado é que, nas sucessivas experiências ao longo dos anos, têm sido propostas basicamente as mesmas condições para que a implementação dos ciclos seja bem-sucedida. Elas, porém, continuam não sendo asseguradas na maioria dos casos, ou não o são de modo satisfatório segundo a percepção de professores e outros atores sociais diretamente envolvidos com as mudanças.

Considerando que a introdução dos ciclos no ensino fundamental não representa mera mudança nos detalhes do funcionamento da escola, mas envolve uma profunda modificação em sua cultura, a conclusão é que muitos esforços ainda serão necessários para que os ciclos venham a se consolidar como estruturas e práticas inovadoras e para que possam constituir-se como uma nova forma de conceber a escola, mais democrática e afinada com as exigências contemporâneas. 


\section{Ciclos: abrangência e configuração no território nacional}

A bibliografia disponível sobre os ciclos alerta para o fato de que os dados estatísticos disponíveis devem ser considerados com cautela, pois os instrumentos de coleta ainda não são adequados para registrar, com precisão, as informações sobre os diversos tipos de organização vigente nas escolas e as respectivas matrículas de seus alunos, permitindo tão somente uma visão aproximada a respeito da cobertura escolar. Um dos principais motivos dessa imprecisão é que existem escolas com organização mista: adotam ciclos e séries. Como as informações censitárias são coletadas tomando por base apenas as unidades escolares, torna-se impossível obter o número exato de alunos matriculados em um e outro regime nesses casos (Barretto e Mitrulis, 2001; Franco, 2003).

Os estudos indicam que os ciclos ainda constituem uma opção minoritária em relação à forma de organização da escola, mas apontam um incremento expressivo das escolas com ciclos nos anos 90.

Considerando o conjunto de escolas brasileiras com ensino fundamental em 2002, públicas e privadas, encontra-se que $19,4 \%$ organizavam o ensino fundamental em ciclos; 10,9\% delas adotavam unicamente ciclos e $8,5 \%$ combinavam ciclos e séries, conforme dados do censo escolar do Inep. Ainda segundo esta fonte, o percentual de alunos matriculados exclusivamente no regime seriado, nesse mesmo ano, era de 62,2\%, enquanto aqueles matriculados em escolas que possuíam unicamente ciclos ou que adotavam regimes mistos constituíam 37,8\% da população escolar. Reiterando-se, portanto: o que se pode afirmar com certeza é que a maioria dos alunos do ensino fundamental freqüenta escolas seriadas nos dias atuais. Há que se observar também que as matrículas em escolas unicamente organizadas em ciclos estão concentradas na Região Sudes- te, em particular nos estados de São Paulo e Minas Gerais, que juntos acolhem 85,3\% dos alunos que nelas estudam (Sousa e Alavarse, 2003). Além disso, há mais escolas com ciclos nas redes de capitais do que nas de seus respectivos estados, como destaca Franco (2003).

Embora sob a mesma denominação ciclos -, observa-se grande diversidade de arranjos adotados pelas redes públicas de ensino quanto à sua duração, o que pode ser um indicador de orientações e motivações diversas dos gestores das políticas educacionais.

Quadro 1: Número de ciclos e tempo de sua duração em redes públicas -2000

\begin{tabular}{|c|c|c|c|c|c|}
\hline & \multicolumn{3}{|c|}{$\begin{array}{c}\text { Duração de cada ciclo } \\
\text { em anos }\end{array}$} \\
\hline $\begin{array}{c}\mathrm{N}^{\circ} \text { de } \\
\text { ciclos }\end{array}$ & $\begin{array}{c}1^{\circ} \\
\text { ciclo }\end{array}$ & $\begin{array}{c}2^{\mathbf{0}} \\
\text { ciclo }\end{array}$ & $\begin{array}{c}3^{\circ} \\
\text { ciclo }\end{array}$ & $\begin{array}{c}4^{\mathbf{0}} \\
\text { ciclo }\end{array}$ & $\begin{array}{c}\mathrm{N}^{\mathbf{0}} \\
\text { redes }\end{array}$ \\
\hline 1 & 2 & & & & 4 \\
\hline 1 & 4 & & & & 4 \\
\hline 2 & 2 & 2 & & & 4 \\
\hline 2 & 2 & 4 & & & 1 \\
\hline 2 & 4 & 4 & & & 6 \\
\hline 3 & 3 & 3 & 3 & & 6 \\
\hline 3 & 2 & 2 & 2 & & 1 \\
\hline 3 & 3 & 3 & 2 & & 1 \\
\hline 4 & 3 & 2 & 2 & 2 & 3 \\
\hline 4 & 2 & 2 & 2 & 2 & 7 \\
\hline
\end{tabular}

In: Sousa e Alavarse (2003, p. 79) Dados de estudo efetuado com amostra abrangendo 37 redes públicas pelo NEPP/Unicamp, 2001.

As evidências trazidas por esta amostra sugerem a oportunidade de investigações que se voltem para uma análise comparativa dessas opções, à luz das políticas estaduais ou municipais dos respectivos estados e municípios, possibilitando revelar possíveis explicações ou justificativas para os projetos em realização.

Uma primeira mirada nos dados dá margem a alguns comentários e questionamentos.

A diversidade encontrada na duração dos ciclos e dos arranjos entre séries e ciclos nas diferentes redes poderá se tornar um complicador para os sistemas de ensino, tendo em conta não só a grande mobilidade da população brasileira, como também a necessidade de articulação das políticas de educação no âmbito das unidades federadas. 
Várias redes escolares têm incorporado os alunos do último ano da educação pré-escolar ao primeiro ciclo, de modo a conformar um ensino fundamental de nove anos. Essa ampliação, sancionada pelo Plano Nacional de Educação (Brasil, 2001), vem sendo adotada também por redes seriadas. Tal iniciativa, em grande parte, pode ser atribuída ao Fundef, uma vez que a incorporação de alunos no ensino fundamental aos seis anos resulta em ampliação do número de matrículas nesta etapa de ensino, referência tomada para cálculo do montante de recursos destinados à manutenção do ensino obrigatório.

Ora, a possibilidade aberta pela legislação não foi acompanhada de uma revisão das orientações curriculares do ensino fundamental, tendo em conta o aumento da sua duração. Nessas circunstâncias, é possível que, nos regimes de ciclos, as crianças menores venham a ter melhor condição de receber um tratamento pedagógico mais adequado e que lhes assegure a continuidade nos estudos do que em escolas seriadas. Provavelmente, nas escolas seriadas, ao invés de se beneficiarem com a medida, muitos alunos estarão sendo prejudicados com a antecipação da possibilidade de serem reprovados antes mesmo de terem completado sete anos de idade.

Várias iniciativas de periodização dos ciclos buscam justificá-la recorrendo a teorias do desenvolvimento infantil. Entretanto essas teorias se reportam a aspectos interiores do desenvolvimento dos sujeitos, que não são passíveis de recortes como os necessários para a definição de ciclos de dois, três ou mais anos. Vale lembrar também que o próprio sistema escolar possui grande poder de periodizar e moldar socialmente certas etapas da vida.

Assim sendo, talvez seja interessante prestar mais atenção aos motivos propriamente escolares ou pedagógicos que levam à definição da duração dos ciclos. Esse é o caso das justificativas evocadas para a criação dos ciclos intermediários, que deliberadamente procuram induzir ao convívio e colaboração mais intensos os professores polivalentes, das classes ini- ciais, habituados a ensinar todos os componentes curriculares e os professores especialistas nos diferentes componentes curriculares, que trabalham com várias turmas. A intenção é que entre eles se consolide a concepção de escola única, não cindida por uma diferenciação formal de habilitações e posturas docentes

Aliás, no limite, a concepção de educação subjacente aos ciclos não sustenta a idéia de segmentação, seja em dois, três ou em qualquer número de agrupamentos. Estes podem ser entendidos como expressão de uma organização necessária ao momento de transição, em que se está vivendo um processo de ruptura com a escola seriada.

\section{Ensaios e pesquisas sobre ciclos: algumas evidências}

Pari passu com as políticas que têm levado à introdução dos ciclos, tem se multiplicado uma literatura de teor predominantemente ensaístico, voltada seja para a problematização e análise dos fundamentos, seja para as condições que se impõem ao trabalho escolar quando se tem como alvo a adoção de uma organização não seriada de ensino.

A contribuição desses estudos deve ser ressaltada, pois eles trazem elementos que permitem apreciação dos princípios em que se assentam as perspectivas de organização da escola em ciclos, que são de natureza política, social, econômica, psicológica e pedagógica. Possibilitam também dimensionar a complexidade da sua implementação, apontando aspectos da estrutura e funcionamento das escolas, do currículo e da avaliação, da formação e envolvimento dos professores nas mudanças pretendidas, da participação dos pais e de outros atores, enfim, da cultura da escola, que são profundamente afetados com a introdução dos ciclos, pressupondo desde um confronto com valores que tradicionalmente têm pautado de modo dominante a organização escolar, até condições que se fazem necessárias para que as propostas não se traduzam apenas na extinção da reprovação 
Assim como a maioria das escolas organizadas em ciclos está situada nos estados de São Paulo e Minas Gerais, os artigos sobre o tema também se concentram nessas experiências, focalizando principalmente a implementação dos ciclos básicos de alfabetização. Nos anos mais recentes surgiram várias publicações sobre o sistema de progressão continuada, introduzido na rede estadual paulista no final dos anos 1990. Quanto às políticas municipais, as mais estudadas são a da capital de São Paulo e a de Belo Horizonte.

A despeito das controvérsias suscitadas pela introdução dos ciclos nas redes escolares, as quais têm envolvido os profissionais do ensino básico, pais e alunos, estudiosos do assunto e a população em geral e sido, em parte, alimentadas pela mídia, são ainda escassas as pesquisas direcionadas à análise dos efeitos produzidos pelas eventuais mudanças ocorridas nas escolas e nos sistemas de ensino após a adoção dessas medidas.

Entre os estudos que se voltam para a análise de resultados e impactos dessas políticas, observa-se que a maior parte trata do tema referindo-se também aos ciclos de alfabetização no final da década de 1980 e início de 1990
(Sousa et al., 2003). Ultimamente, investigações que procuram aliar dados de expansão dos ciclos à avaliação do rendimento dos alunos no âmbito dos sistemas e às condições de ensino nas escolas, começam a oferecer novas pistas de abordagem e de entendimento da questão, como as feitas por Ferrão; Beltrão; Santos, 2002; Franco, 2003 e Fernandes, 2003. 0 que se pode afirmar até agora, segundo algumas dessas pesquisas, é que os propalados argumentos de que os ciclos e a progressão continuada baixariam o nível do ensino não encontram evidências nos dados empíricos.

A seguir são indicados estudos relativos às propostas de redes de ensino, que se constituem em referência obrigatória para os que venham a desenvolver pesquisas e avaliações sobre o tema.

\section{Municípios de capitais: algumas contribuições inovadoras}

Um recorte particular de textos que abordam experiências com traços inovadores, como as levadas a cabo em alguns municípios, pode trazer mais luz sobre certas orientações que vêm se tornando paradigmáticas. É o que faremos a seguir.

Quadro 2: Iniciativas estudadas e suas referências bibliográficas

\begin{tabular}{|c|c|}
\hline Unidade Federada ou Município & Referência bibliográfica \\
\hline Belo Horizonte & $\begin{array}{l}\text { Amaral, 2002; Arroyo, 1999a-b; Dalben, 1998; Dalben, 2000a-b; Fortes, 1997; Freitas, 2000a; } \\
\text { Giusta; Euclides; Ramón, 1999; Silva e Mello, 2001; Soares, 2000; Souza, 2000; Zaidan, } 1999 .\end{array}$ \\
\hline Blumenau & Andrade, 2002 \\
\hline Ceará & Alexandrino, 2000; Nunes, 2001 \\
\hline Minas Gerais & $\begin{array}{l}\text { Alencar, 1989; Antunes; Souza, 1992; Fernandes; Franco, 2001; Pereira, 1988; Vianna, 1992a-b; } \\
\text { Vianna; Squarcio; Vilhena, } 1992\end{array}$ \\
\hline Niterói & Fernandes, 2003 \\
\hline Paraná & Negri, 1994 \\
\hline Ponta Grossa & Mainardes, 1995a-b \\
\hline Porto Alegre & Azevedo, 1997; Krug, 2001 \\
\hline Santa Catarina & Dutra; Pereira; Auras, 1984; Sena; Medeiros, 1984 \\
\hline São Paulo / Estado & $\begin{array}{l}\text { Ambrosetti, 1989, 1990; Arcas, 2003; Arelaro, 1988a-b-c; Barretto, 1987, 1992; Barretto; Alves, } \\
\text { 1987; Bertagna, 2003; Bonel, 1993; Brito, 2001; Cruz, 1994; Davis; Espósito, 1992; Duran, 1990; } \\
\text { 1995; Frehese, 2001; Freitas, 2000b; Fusari, 2001a-b; Guimarães, 2001; Jeffrey, 2001; } \\
\text { Magalhães, 1999; Negri, 1994; Neubauer, 2000; Neubauer; Davis; Espósito, 1996; Palma Filho, } \\
\text { 1989; Palma Filho; Alves; Duran, 2003; Renazzo, 1987; Silva, 1990, 1991; Silva; Davis, 1993; } \\
\text { Steinvascher, 2003; Viegas, } 2002\end{array}$ \\
\hline São Paulo / Município & Alavarse, 2002; Borges, 2000a-b; Cortella, 1992; Jacomini, 2002; Paro, 2001 \\
\hline Vitória da Conquista & Leite, 1999 \\
\hline
\end{tabular}

Fonte: Sousa et al., 2003 e indicações complementares. 
Municípios brasileiros de capitais possuem, de modo geral, situação privilegiada em relação às suas redes de ensino quando se as compara com as de seus respectivos estados. Têm redes menores do que as estaduais dentro dos próprios limites de seu território, e estas tendem a ser mais bem providas de recursos materiais em relação ao número de alunos que atendem; seus recursos humanos usualmente são mais qualificados. Essas condições são especialmente mais favoráveis nas redes das capitais dos estados de economia mais dinâmica.

As redes de ensino desses municípios costumam também usufruir com maior intensidade do intercâmbio com as universidades, em especial com as públicas e mais bem conceituadas, geralmente sediadas na capital. Esse intercâmbio manifesta-se na colaboração para a formulação e implementação do currículo, formação de professores, desenvolvimento de projetos de pesquisa e intervenção nas escolas, acompanhamento e avaliação de programas e, por vezes, é decisivo até mesmo na própria formulação das políticas municipais de educação.

Na década de 1990 o Partido dos Trabalhadores (PT), criado em 1980, ganha eleições em importantes capitais do país. Os projetos educacionais dessas capitais se beneficiam, de uma forte coesão ideológica em torno dos princípios de participação e gestão democrática e de uma postura política francamente dirigida para o social, advinda de orientação do próprio partido. Entre as áreas sociais, a educação é, certamente, a que conta com contribuição muito significativa de seus intelectuais, muitos deles com projeção nacional e, em alguns casos, como no de Paulo Freire, de indiscutível representatividade também no plano internacional. Os projetos beneficiam-se ainda das discussões, iniciativas e lutas travadas pelos governos de oposição dos anos 1980, particularmente nos estados das Regiões Sul e Sudeste, que tiveram participação decisiva na transição do país para o Estado de Direito.

Essas circunstâncias contribuíram para que em alguns desses municípios as experiên- cias de introdução dos ciclos escolares adquirissem características inovadoras.

São Paulo, Belo Horizonte e Porto Alegre são capitais que se enquadram nesse perfil. São Paulo teve o primeiro mandato do PT entre 1989 e 1992, que retornou ao governo na atual gestão (2000 a 2004). Em Belo Horizonte a gestão petista correspondeu ao periodo de 1993 a 1996, à qual se seguiram dois mandatos consecutivos do Partido Socialista Brasileiro (PSB), que deram, em grande medida, continuidade ao projeto educacional de seus antecessores petistas. A prefeitura de Porto Alegre também foi ganha pelo PT em 1989, que tem se conservado no poder em gestões sucessivas até hoje.

As três redes, embora com tamanhos muito diferentes, apresentam um amplo espectro de atendimento à educação básica, sendo responsáveis pela manutenção de creches, préescolas, ensino fundamental, ensino médio regular e ou curso normal, educação especial e educação de jovens e adultos.

0 projeto educacional para a educação básica e, em particular para o ensino fundamental, quando da opção por implantar a organização do ensino em ciclos, apresentava algumas características comuns nesses três municípios, embora com traços que o singularizassem em cada um deles. Com o propósito de oferecer uma educação de corte popular e democrático que assegurasse a todos o direito ao conhecimento e à formação cidadã, essas gestões possuíam, como traços comuns:

- assunção de uma postura radical de reversão das estruturas excludentes da escola e da cultura que a legitima;

- forte acento no trabalho coletivo que envolva toda a comunidade escolar (alunos, profissionais da escola, pais, comunidade), na formulação e implementação do projeto político-pedagógico da escola;

- nova relação com o conhecimento, buscando significados para o conteúdo escolar que estabeleçam uma relação mais dialógica entre 
as vivências dos alunos e o conhecimento sistematizado, numa perspectiva globalizadora e interdisciplinar;

- especial empenho na superação do regime seriado e suas conseqüências em relação à retenção e agravamento da seletividade escolar.

\section{São Paulo}

No município de São Paulo a implementação dos ciclos no ensino fundamental ocorreu em 1992, ao final do primeiro mandato do PT, e abrangeu todas as escolas municipais. Na ocasião, a rede contava com 353 escolas, mais de 440 mil alunos e quase 30 mil professores (Alavarse, 2002).Tratava-se de uma medida ousada para a época. Era a primeira vez, desde as iniciativas estaduais de introdução dos ciclos de alfabetização na década de 1980, que se propunha a sua extensão para o ensino fundamental como um todo. Além disso, a implantação dos ciclos deveria ser imediata e não gradual. Também pela primeira vez foram sistematizados princípios de um novo modelo de escola que terminou por disseminar-se mais tarde.

A iniciativa inseria-se em um conjunto de ações educacionais desencadeadas nos anos 1989 a 1992, que se pautaram nos princípios de participação, descentralização e autonomia. Desses princípios derivaram-se diretrizes educacionais, dentre as quais a "nova qualidade de ensino", que abarca, ao lado de outras iniciativas, a reorientação curricular, com destaque para a interdisciplinaridade, em que se inseriu a proposta de ciclos dessa administração. Sua regulamentação foi expressa no novo Regimento Comum das Escolas Municipais, resultante de discussões com professores, alunos e pais, apresentando-se como alternativa capaz de contribuir para a democratização do ensino.

Nessa ocasião, o ensino fundamental foi estruturado em três ciclos: inicial (antigas $1^{\text {a }}, 2^{\text {a }}$ e $3^{\text {a }}$ séries), intermediário (antigas $4^{\text {a }}, 5^{\text {a }}$ e $6^{\text {a }}$ séries) e final (antigas $7^{\text {a }}$ e $8^{\text {a }}$ séries), com destaque à necessidade de a avaliação se consti- tuir em atividade contínua e qualitativa, cujos resultados deveriam ser registrados em relatórios semestrais e discutidos com os alunos e seus responsáveis. Os registros síntese do desempenho escolar passaram de notas para conceitos. Foi prevista a possibilidade de reprovação do aluno ao final de cada ciclo e, neste caso, deveria o aluno refazer o último ano do ciclo correspondente.

Entre as condições propiciadas para dar suporte à nova organização curricular, destacam-se: a criação de horários coletivos de trabalho na escola, estimulando-se, por exemplo, os professores a assumirem a jornada de trabalho integral (pela qual recebem por 40 aulas semanais, sendo 25 com alunos, oito em horário coletivo, três em tarefas individuais cumpridas na escola e quatro destinadas a atividades individuais livres, fora da escola); a reorientação da ação supervisora, baseada em um trabalho articulado entre as instâncias intermediárias do sistema e as escolas, bem como no estímulo e apoio para o desenvolvimento de projetos pelas unidades escolares, capazes de responder às suas demandas específicas.

A proposta de reorganização da escola em ciclos, implantada em clima de grande envolvimento dos professores e outros atores educacionais com o projeto de reestru-turação curricular, não teve continuidade nos moldes originalmente previstos, em virtude das vicissitudes decorrentes da alternância de partidos no poder e das diferenças ideológicas entre os grupos gestores que estiveram no comando do municipio entre os anos 1990 e os dias atuais. No período 1993-1996, o Partido Popular (PP), de forte acento conservador, assume a prefeitura de São Paulo e, embora não tenha alterado formalmente a organização de ensino vigente, não investiu em sua consolidação. Ao contrário, iniciativas que colocavam em questão a sua validade foram desencadeadas, como a consulta aos professores realizada em 1994 acerca da manutenção ou não dos ciclos ou a tentativa, no início do governo, de implantar a Qualidade Total como referência para a gestão do sistema. 
0 prefeito fez seu sucessor para a gestão seguinte (1997-2000). Nesse período, por decreto da administração municipal, altera-se a organização dos ciclos para acompanhar o agrupamento proposto na rede estadual paulista; eles passam a ser dois apenas, de quatro anos cada, com possibilidade de reprovação ao final de cada ciclo.

Essa organização foi mantida na gestão 2001-2004, em que o Partido dos Trabalhadores retorna ao poder. A opção pelos ciclos de quatro anos instaura porém a antiga divisão entre primário e ginásio, frustrando o intento de melhor articulação do projeto educacional da escola completa de oito anos. Além disso, não tem sido acompanhada de iniciativas e condições de trabalho que resguardem e sustentem os fundamentos da reorganização do ensino.

No período que decorre da implantação dos ciclos aos anos recentes, a rede do município, que já era uma das grandes redes do pais, ampliou ainda mais o atendimento dos alunos, por força das pressões da própria administração estadual, que tem se concentrado na expansão do ensino médio deixando aos municípios maior responsabilidade quanto à oferta de vagas no ensino fundamental, assim como pela pressão proveniente do crescimento da própria demanda escolar. Na última gestão, que concebe a educação como elemento fundamental da rede de proteção social da cidade, os projetos desenvolvidos com vistas a aumentar o vínculo com a comunidade têm na escola o centro irradiador de programas sociais mais abrangentes, o que contribui para o aumento da procura pelas unidades escolares do município (São Paulo, 2003).

À parte os Centros Educacionais Unificados (CEUs), para os quais grande montante de verbas da prefeitura vem sendo carreado, as escolas que constituem a maioria da rede municipal paulista não têm recebido o devido aporte de recursos, nem o apoio pedagógico necessário para fazer frente às novas exigências de atendimento. A multiplicação de classes superlotadas, a rotatividade do corpo docente nos bairros periféricos e a falta de um projeto educativo capaz de catalisar os esforços dos professores, circunstâncias essas agravadas pela quantidade de escolas localizadas em regiões com altos índices de violência, certamente são condições que não favorecem o desenvolvimento das potencialidades inovadoras enunciadas na proposta dos ciclos.

Sem a devida mobilização dos educadores em torno do projeto de implementação dos ciclos durante as várias gestões que se sucederam à sua introdução na rede, mobilização essa potencialmente capaz de alimentar um processo permanente de discussão, questionamento e busca de soluções para enfrentar os desafios propostos por essa reestruturação, os ciclos na capital de São Paulo tendem a funcionar como meros arranjos organizacionais que impedem a reprovação dos alunos. Continuam assim a reproduzir a lógica da escola seriada, sem conseguir mudar a sua face.

\section{Belo Horizonte}

A gestão que se inicia em 1993, no município de Belo Horizonte, inaugura um processo de mudanças na rede escolar, informado por um projeto político-pedagógico formulado em torno de alguns eixos norteadores, que sintetizam, de forma consistente e articulada, aspectos dos mais relevantes do ideário contemporâneo de educação. A proposta político-pedagógica da Escola Plural, como passa a ser chamada, veio a público em 1994 e começou a ser implementada no ano seguinte.

Ela não pretende mudanças pontuais; busca antes chegar às grandes questões que dão sentido ao pensar e fazer da educação. Implica um movimento de confronto com pensamentos e valores, representações, culturas escolares e profissionais, com a própria imagem dos educadores.

A proposta da Escola Plural não só foi divulgada pela prefeitura, como também o próprio Ministério da Educação encarregou-se de disseminá-la mais amplamente pelo pais, publicando-a na Série Inovações (Brasil,1994). Por 
este documento verifica-se que o seu projeto político-pedagógico está estruturado em torno de quatro núcleos vertebradores.

0 primeiro deles reporta-se aos eixos norteadores, a saber:

- propor uma intervenção coletiva mais radical na realidade da escola;

- revelar sensibilidade com a totalidade da formação humana;

- considerar a escola como tempo de vivência cultural;

- considerar a escola como espaço de produção coletiva;

- levar em conta as virtualidades educativas da materialidade da escola;

- assegurar a vivência de cada idade de formação sem interrupção;

- proporcionar socialização adequada a cada idade-ciclo de formação;

- criar nova identidade da escola e de seus profissionais.

Além de propor uma mudança profunda na cultura escolar, a Escola Plural pretende também redefinir aspectos significativos da sua estrutura e funcionamento, flexibilizando os espaços e os tempos escolares de modo a permitir que as novas formas de organização favoreçam o desenvolvimento de experiências formadoras. Nesse sentido, a rede escolar deve dar guarida a experiências com salas ambiente, módulos, aulas geminadas, novos critérios de agrupamento, horários mais flexíveis, integração extra-turno, provas interdisciplinares, classes de aceleração, turmas de recuperação, turmas intermediárias, períodos para reuniões e outras.

0 segundo núcleo vertebrador diz respeito à reorganização dos tempos escolares, mediante a criação dos ciclos de formação. Eles pautam-se na vivência de cada idade de formação, a saber, a infância, a pré-adolescência e a adolescência, que não devem estar sujeitas a interrupções. Os ciclos de formação possibilitam à escola assegurar a socialização adequada a cada idade-ciclo, procurando reduzir as ruptu- ras provocadas pela repetência no processo educacional. Ênfase redobrada é atribuída à função socializadora e formadora do convívio dos alunos da mesma idade, propiciada pelos ciclos, os quais contribuem para que diferenças de raça, classe, gênero ou ritmo de aprendizagem deixem de ser evocadas como justificativas para rupturas no processo de formação. A lógica da aprendizagem, que trabalha com tempos predefinidos, reduzidos a períodos cada vez mais curtos para o domínio de conhecimentos e habilidades, deve agora se submeter à lógica da socialização apropriada a cada idade de formação, à lógica da formação de identidades equilibradas, da vivência da cultura. Emerge assim nova relação com o conhecimento, que tem a ver com a afirmação de que cada etapa de formação da criança e do adolescente deve ser entendida como um tempo específico de vivência de direitos. A escola é, portanto, repensada como tempo e espaço de exercício da cidadania e dos direitos no presente, lugar em que os alunos devem ter condição de usufruir, o mais plenamente possivel, o direito à educação.

Os ciclos na Escola Plural são três, de três anos cada, sendo que o primeiro incorpora as crianças de seis anos da pré-escola, vindo a constituir um ensino fundamental de nove anos, que antecede a possibilidade referendada posteriormente pelo Plano Nacional de Educação (2001), de ampliação dos anos de escolaridade obrigatória. 0 ciclo intermediário, que atende as crianças na faixa aproximada de 9 a 11 anos, é defendido com especial empenho porque deve propiciar maior integração dos professores generalistas e professores especialistas nos diferentes componentes curriculares.

0 terceiro núcleo vertebrador tem a ver com os processos de formação plural. Busca-se aqui uma nova identidade do profissional da escola. Tempos remunerados de estudo e pesquisa, expressão da consciência dos profissionais sobre o desempenho no trabalho, ganham renovada importância no bojo das mudanças que se quer realizar. Alarga-se também a concepção de formação profissional continuada. 
Em artigo publicado em 1999, Arroyo (1999a), um dos formuladores da Escola Plural, melhor explicita a concepção de formação dos profissionais envolvidos com os ciclos de formação, também chamados ciclos de desenvolvimento humano. As propostas pedagógicas que concebem os ciclos como ciclos de formação ou de desenvolvimento humano supõem que a melhor estratégia é a de partir da formação que os docentes já possuem, assumir que a função de educador carrega funções definidas socialmente e recuperar o que há de permanente no ofício de professor. Não se trata pois de inventar novas incumbências e, sim, de criar situações coletivas que possibilitem reforçar o que há de mais permanente e duradouro na função social e cultural dos profissionais da educação e que eles já põem em ação na sua prática. Procurase recuperar a concepção da educação básica como direito ao desenvolvimento humano, à realização humana. É a retomada da tradição humanista, radicalizada nas lutas pelos direitos sociais, pela emancipação humana, pela igualdade e pelo respeito à diferença, visão que se contrapõe àquela que reduziu o direito à educação ao ato de receber da escola as credenciais e competências demandadas pelo mercado seletivo e a preparar para a empregabilidade. Nos termos dessa concepção mais radical da educação básica, a formação docente ocorre concomitantemente com a desconstrução de culturas escolares e profissionais e com o processo de desenvolvimento humano, social e cultural dos professores.

0 quarto eixo vertebrador re-significa a avaliação na Escola Plural. Inserida na nova lógica da inclusão, a avaliação deve incidir, como bem remarca Amaral (2002), sobre os aspectos globais do processo educativo, e estar referida não apenas às questões do processo ensino aprendizagem, com também às relativas à atuação do professor, ao projeto curricular da escola, à organização do trabalho escolar, à função socializadora e cultural, à formação de identidades e construção de valores, enfim, ao projeto político-pedagógico da escola.
Ela está estreitamente vinculada à concepção de aprendizagem que informa os ciclos e pretende redimensionar a ação educativa mediante um processo formativo e contínuo do qual participam todos os atores sociais, com maior ou menor envolvimento. Cria-se o Conselho de Ciclo, onde o desenvolvimento do currículo e a avaliação são discutidos mais amplamente. A avaliação compreende um momento inicial, seguido de procedimentos contínuos calcados em instrumentos variados, e um momento final, sendo que o projeto original da Escola Plural previa a possibilidade de retenção de alunos ao final do ciclo em casos especiais. Limitava porém o tempo de retenção, de modo a não dar margem ao aumento da defasagem do aluno em relação ao seu grupo de idade. ${ }^{2}$

A implantação dos ciclos foi gradual e ocorreu em meio a muita polêmica e a discussões com o objetivo de estudar a proposta e de encontrar maneiras de operacionalizá-la na prática (Dalben,1998). 0 primeiro e o segundo ciclos foram introduzidos em 1995 e o terceiro, em 1996. Mais recentemente houve a criação do ciclo da juventude, equivalente ao ensino médio.

O PSB, que assume a prefeitura de Belo Horizonte em dois mandatos subseqüentes, assegura que o projeto político-pedagógico da Escola Plural mantenha até os nossos dias, portanto, já por doze anos, as suas características principais.

Fugindo à tradição brasileira, segundo a qual as políticas de educação costumam suceder-se umas às outras sem que sejam ajuizadas por avaliações realizadas por meio de procedimentos sistemáticos que permitam uma apreciação menos isenta das medidas adotadas, pode-se dizer que a experiência da Escola Plural é a que mais tem sido acompanhada no país, seja por meio de estudos de caráter estritamente acadêmico, seja por meio de avaliação

2. Posteriormente eliminou-se de vez a possibilidade de retenção. 
externa, determinada pelo Conselho Estadual de Educação de Minas Gerais. Isso parece bom sinal, particularmente porque a política educacional de Belo Horizonte tem-se tornado referência nacional para a prática educativa de muitos municípios e estados brasileiros.

Em 1999, mediante parceria entre a Secretaria Municipal de Educação da capital mineira, a Fundação Ford e a Faculdade de Educação/ Grupo de Avaliação e Medidas Educacionais da Universidade Federal de Minas Gerais (FAE/GAME, UFMG), foi realizada uma avaliação externa do projeto político-pedagógico da Escola Plural, entendido como um projeto de reforma educacional no âmbito do município.

Quatro anos após a implementação da Escola Plural, a rede municipal de ensino de Belo Horizonte possuía 175 escolas, oito mil professores e 180 mil alunos.

A avaliação promovida teve dois propósitos: o de apreciar o projeto do ponto de vista do seu entendimento, implantação e implementação e o de subsidiar, com os dados coletados, os estudos sobre reformas educacionais. Seu delineamento comportou: o estudo da concepção da Escola Plural; a organização de um extenso Banco de Dados administrativos e pedagógicos sobre as escolas da rede; um estudo qualitativo desenvolvido por meio de múltiplos estudos de caso; três estudos de caso de caráter etnográfico. Ainda que recorresse a dados quantitativos, o trabalho desenvolvido foi eminentemente qualitativo, por se entender que se tratava de reforma em construção, na qual as percepções e interpretações dos atores constituíam a fonte mais rica (Dalben, 2000 a; Amaral, 2002).

As recomendações decorrentes do estudo coordenado por Dalben, na perspectiva de consolidação do programa Escola Plural são:

- estruturar parâmetros curriculares básicos, próprios do programa para os três ciclos de formação;

- construir parâmetros apontando competên- cias cognitivas a serem desenvolvidas pelos alunos de cada ciclo, favorecendo a construção de referenciais de avaliação do ensino e da aprendizagem;

- adotar procedimentos que possibilitem a avaliação dos alunos da rede ou estruturar um sistema de avaliação que contemple a questão do conhecimento e do seu uso social, de acordo com os princípios do programa;

- investir em campanha de informação à sociedade sobre o significado da não retenção no programa;

- desenvolver projetos educativos com a comunidade para construir nova mentalidade sobre o sentido e significados da escolarização básica;

- continuar a estimular a prática de elaboração de projetos pedagógicos próprios de cada escola, segundo sua realidade e princípios do programa;

- reestruturar o programa de formação de professores a ser assumido integradamente pela Secretaria Municipal e seu Centro de Aperfeiçoamento dos Profissionais de Educação (CAPE) e escolas;

- colocar em pauta propostas de discussão sobre atendimento a alunos portadores de dificuldades específicas e propostas de orientação, no caso de absenteísmo dos alunos.

Como parte dos trabalhos desenvolvidos na pesquisa de avaliação, foi publicada também uma coletânea de artigos de autores que dela participaram e que se comprometeram a dialogar com os professores sobre as questões que emergiram durante o processo de avaliação. Esses textos, além de procurar contextualizar a experiência da Escola Plural em relação à tradição de inovação já presente em outros momentos da rede da capital mineira, abordam temas como a imagem pública do programa, os projetos de trabalho desenvolvidos nas escolas, a avaliação escolar e a forma como se manifestam as relações de poder quando não há retenção de alunos, a prática pedagógica e os ciclos de formação (Dalben, 2000b). 
Fazendo uma releitura de 31 relatórios elaborados por pesquisadores que participaram da avaliação da Escola Plural e que constam do Banco de Dados, Ana Lúcia Amaral procura identificar as repercussões das atuais políticas públicas de avaliação nas práticas pedagógicas e processos avaliativos das escolas da rede. 0 trabalho evidencia os desencontros das políticas entre si e os desencontros que provocaram nas práticas das escolas (Amaral, 2002).

Os estudos até agora realizados sobre a Escola Plural deixam claro o fértil esforço coletivo de construção de uma escola, cheia de controvérsias naturalmente, mas prenhe de iniciativas capazes de delinear uma nova maneira de pensar e de fazer a educação para todos.

\section{Porto Alegre}

A ruptura com a seriação, na rede de ensino de Porto Alegre, articula-se a um movimento mais amplo de democratização do Estado, desencadeado com a Administração Popular - Partido dos Trabalhadores - à frente da gestão municipal a partir de 1989. A caracterização desta iniciativa, feita a seguir, tem como referência considerações apresentadas por Krug (2001) e documentos da Secretaria Municipal de Educação de Porto Alegre (Porto Alegre, 1999 e 2003).

No período de 1989 a 1992, os registros disponíveis indicam que o foco da política educacional recaiu na alfabetização, sob o compromisso de sua garantia às crianças das séries iniciais do ensino fundamental.

Foi na administração que se realizou no período 1992 a 1996 que foi delineada a proposta de reorganização do ensino. Nesse momento, a ênfase governamental direcionou-se à gestão democrática, com a criação de canais de decisão coletiva e colegiada, desencadeando-se a Constituinte Escolar, que culminou com o $1^{\circ}$ Congresso Constituinte da Rede Municipal (1995), cujos debates focalizavam alternativas para se evitar a exclusão escolar. Apresenta-se, então, como uma das alternativas, a reorgani- zação curricular do ensino por "ciclos de formação", com o propósito de garantir a aprendizagem de todos os alunos, sem interrupções em sua trajetória escolar. A proposta acompanha as iniciativas das prefeituras de São Paulo e de Belo Horizonte no seu intento básico.

A implementação na rede deu-se de modo gradual, cabendo às escolas a decisão quanto à sua adesão à nova proposta curricular, que, em sintese, apresenta as seguintes características: os alunos são organizados por idade, dos seis aos quatorze anos, em três ciclos de três anos cada, os quais têm como referência as fases de desenvolvimento (infância, pré-adolescência e adolescência). Não há reprovação, sendo previstas alternativas para apoiar os alunos que apresentarem dificuldades específicas em sua trajetória escolar, tais como laboratórios de aprendizagem, professores itinerantes e sala de integração e recursos. Entre as condições propiciadas para garantir a reorganização curricular destacam-se: espaço/tempo para o trabalho coletivo na escola, formação permanente dos profissionais da educação, supervisão pedagógica às escolas e envolvimento de alunos, famílias e funcionários na discussão do currículo.

Como um dos principais caminhos para organização do trabalho escolar, é proposto o “complexo temático", que visa orientar interdisciplinarmente o conteúdo do processo de ensino e de aprendizagem da escola de modo a articular conceitos em diferentes níveis de profundidade, sendo os fenômenos tratados a partir de relações estabelecidas entre a experiência dos alunos e as áreas do conhecimento. Destaque é dado à função formativa da avaliação, que deve servir de apoio ao redimensionamento da ação pedagógica e educativa, voltando-se para o conjunto da escola e não apenas para o aluno.

Quanto a eventuais alterações na proposta dos "Ciclos de Formação" em Porto Alegre, tal como originalmente delineada, bem como quanto ao seu desenvolvimento e resultados, não foram localizados estudos e pesqui- 
sas. Como se pode identificar na bibliografia apresentada, há apenas uma dissertação de mestrado sobre tal iniciativa (Krug, 2001), que trata da apresentação de seus princípios e fundamentos, mas não de suas decorrências. A autora, que foi uma das assessoras da proposta, tem um registro em seu estudo que permite supor ter havido alterações na orientação dada à rede, quando menciona que "cerca de setenta pessoas (...) saem da Smed ao final de 2000, e mais trinta (...) são convidadas a se retirar pela nova Administração, a partir de 2001" (op.cit, p. 113), embora tenha permanecido à frente da administração municipal o Partido dos Trabalhadores.

De acordo com os registros disponíveis no censo escolar do lnep para 2002, a rede da capital gaúcha contava com 46 escolas organizadas em ciclos e um total de 48.715 matrículas no ensino fundamental.

\section{A propósito das experiências em foco}

A dimensão das redes escolares municipais e, particularmente, a proporção do atendimento por elas oferecido em relação ao que é ofertado pela rede estadual no mesmo município são aspectos que merecem ser aprofundados em estudos interessados na apreciação do impacto da sua contribuição sobre a qualidade do ensino da população residente nessas capitais.

Em redes escolares muito grandes como a paulistana, as questões suscitadas pela implementação de reformas, independentemente da vontade política dos governantes que as introduzem, provavelmente serão mais complexas do que em redes pequenas como a de Porto Alegre. Entretanto, é esperável que certos logros, quando obtidos pelos alunos de redes extensas, tenham repercussões mais amplas junto à população.

Um outro aspecto a considerar também é que as repercussões das reformas que se propõem a introduzir uma nova lógica na es- cola mediante os ciclos têm extrapolado, em muito, os limites das próprias redes em que elas foram implementadas. 0 que se observa no Brasil é que as formulações sobre os ciclos se enriquecem umas com as outras e que essa mútua fertilização tende a proliferar à medida que a adoção dos ciclos assume foros de política nacional.

0 exame da literatura referente às três capitais sugere, por sua vez, que é crucial a importância do papel atribuído aos ciclos pelas diferentes gestões das redes públicas. Sempre que o propósito da organização em ciclos não ocupa um lugar central nas políticas de educação, ele perde em parte a sua condição potencial de desafiar as velhas estruturas excludentes e toca apenas de maneira superficial na cultura escolar.

\section{Ciclos: conhecimento em construção}

0 que esta revisão bibliográfica preliminar deixa claro, é que os ciclos como uma forma de organização da escola e de desenvolvimento do currículo sob uma perspectiva democrática e inclusiva estão em vias de ser. construídos. Nesse processo de construção encontram-se envolvidos os formuladores de políticas, os educadores e alunos - que os criam e recriam no cotidiano da escola - , a comunidade escolar e os estudiosos do assunto.

Embora na literatura analisada haja elementos preciosos para a compreensão do estágio atual em que se encontram as questões pertinentes aos ciclos no Brasil, as políticas em curso demandam maiores investigações. Nessa perspectiva são oportunas e relevantes não só pesquisas de cunho descritivo e analítico, mas também estudos de caráter propositivo que abarquem as dimensões de concepção e formulação das políticas, bem como a sua implementação. Há também necessidade de criar instrumentos para acompanhamento mais sistemático e avaliação de seus impactos, seja no nível da trajetória pessoal dos alunos, seja 
em termos de suas conseqüências mais amplas. Muito há que avançar em termos de estudos que sejam capazes de propiciar respostas que remetem a uma questão de base: como construir uma escola que seja efetivamente capaz de acolher e ensinar a todos aqueles a quem ela historicamente sempre marginalizou?

Como se trata de uma iniciativa que supõe transformações desde o âmbito do sistema até as unidades escolares e as práticas de sala de aula, evidenciam-se diversos focos a serem investigados. No entanto, o caráter estrutural da transformação da escola seriada impõe que se contemplem nas investigações, para além de aspectos mais diretamente pedagógicos, as estruturas, processos e valores em que historicamente se assenta a instituição escolar. Intensificar a interlocução entre os pesquisadores e as redes de ensino, gestores e docentes, pode ser um caminho promissor no sentido de conferir maior densidade ao delineamento de alternativas de intervenção. 0 incremento de uma relação dialógica entre os que estão diretamente envolvidos nas escolas, os dirigentes e pesquisadores, certamente deve alimentar, pela produção conjunta, experiências que dêem concretude à dimensão democrática subjacente à reorganização do ensino em ciclos.

\section{Obras analisadas}

ALAVARSE, O. M. Ciclos: a escola em (como) questão. 2002. Dissertação (Mestrado)- Faculdade de Educação, Universidade de São Paulo, São Paulo, 2002.

ALENCAR, R. M. de M. Análise da avaliação do ciclo básico de alfabetização das escolas estaduais de $1^{\circ}$ grau de Minas Gerais. 1989. Dissertação (Mestrado)- Universidade Federal do Rio de Janeiro, Rio de Janeiro, 1989.

ALEXANDRINO, M. C. Organização do ensino em ciclos: a proposta de avaliação da aprendizagem da SEDUC: alguns enviesamentos. Educação em Debate, Fortaleza, ano 21, v. 1, n. 39, p. 42-52, 2000.

AMARAL, A. L. As políticas públicas de avaliação e sua repercussão nas práticas pedagógicas da Escola Plural. Estudos em Avaliação Educacional. São Paulo, n. 26, p. 3-29, jul./dez., 2002.

AMBROSETTI, N. B. Ciclo Básico: o professor da escola pública paulista frente a uma proposta de mudança. 1989. Dissertação (Mestrado)- Pontifícia Universidade Católica-SP, São Paulo, 1989.

Ciclo Básico: uma proposta vista pelas professoras. Cadernos de Pesquisa, São Paulo, n. 75, p. 57-70, nov. 1990.

ANDRADE, M. R. S. de. Organização do trabalho escolar. os tempos e os espaços de formação humana. 2002. Dissertação (Mestrado)- Universidade Regional de Blumenau, Blumenau, 2002.

ANTUNES, A. L.; SOUZA, M. A. de. 0 aluno do CBA: análise de algumas de suas características. Estudos em Avaliação Educacional, São Paulo, n. 6, p. 43-60, jul./dez. 1992.

ARCAS, P. H. Avaliação da aprendizagem no regime de progressão continuada: 0 que dizem os alunos. 2003. Dissertação (Mestrado)- Faculdade de Educação, Universidade de São Paulo, São Paulo, 2003.

ARELARO, L. R. G. Ampliação do período de alfabetização nas séries iniciais. 0 ciclo básico em São Paulo: algumas considerações. Idéias, São Paulo, n. 1, p. 53-55, 1988a.

A (ex)tensão do ensino básico no Brasil: 0 avesso de um direito democrático: uma análise da ação governamental nos últimos 25 anos (1962-1987). 1988b. Tese (Doutorado)- Faculdade de Educação, Universidade de São Paulo, São Paulo, 1988b. 1988c.

A (ex)tensão do ensino básico no Brasil: ainda um desafio político. Em Aberto, Brasília, ano 7, n. 39, p. 37-43, jul./set. 
ARROYO, M. G. Ciclos de desenvolvimento humano e formação de educadores. Educação e Sociedade. Campinas, ano XX, n. 68, p. 143-162, dez. 1999a.

. Experiências de inovação educativa: o currículo na prática da escola. In: MOREIRA, A. F. B. (Org.). Currículo: políticas e práticas. Campinas: Papirus, 1999b. p. 131-164.

AZEVEDO, J. C. de. Ensino por ciclos: a democratização do conhecimento na rede municipal de ensino de Porto Alegre. Pátio, Porto Alegre, v. 1, n. 0, p. 31-32, fev./abr. 1997.

BARRETTO, E. S. de S. Avaliação na escola de $1^{\circ}$ Grau: a experiência da Secretaria da Educação do Estado de São Paulo e a implantação do ciclo básico. Educação e Seleção, São Paulo, n. 16, p. 125-136, 1987.

Organização do trabalho escolar no ciclo básico na perspectiva da superação do fracasso escolar. Idéias, São Paulo, n. 6, p. 101-107, 1992.

BARRETTO, E. S. de S.; ALVES, M. L. Buscando a superação do fracasso escolar na rede estadual paulista. Em Aberto, Brasília, ano 6, n. 33, p. 11-16, jan./mar. 1987.

BARRETTO, E. S. de S.; MITRULIS, E. Os ciclos escolares; elementos de uma trajetória. Cadernos de Pesquisa, São Paulo, n. 108, p. 27-48, nov. 1999.

. Trajetória e desafios dos ciclos escolares no país. Estudos Avançados, São Paulo, v. 15, n. 42, p. 103-140, maio/ago. 2001.

BERTAGNA, R. H. Progressão continuada: limites e possibilidades. 2003. Tese (Doutorado)- Faculdade de Educação, Universidade de Campinas, Campinas, 2003.

BONEL, M. M. O Ciclo Básico: estudo de caso de uma política pública no Estado de São Paulo. 1993. Tese (Doutorado)- Faculdade de Educação, Universidade de Campinas, Campinas, 1993.

BORGES, I. C. N. Políticas de currículo em conflito: uma análise da estrutura curricular em ciclos na Secretaria de Educação de São Paulo (1989-1997). 2000a. Dissertação (Mestrado)- Programa Educação-Currículo, Pontifícia Universidade Católica-SP, São Paulo, 2000a.

Currículo democrático: resistências e possibilidades. São Paulo: Editora Articulação Universidade/Escola, 2000b.

BRASIL, Leis decretos. Plano Nacional de Educação, Lei n.10172, de 9 de janeiro de 2001. Brasília: Senado Federal, 2001.

BRASIL, Ministério da Educação e Cultura. Escola Plural. Proposta político-pedagógica. Brasília: MEC/SEF,1994. Cadernos Educação Básica. Série Inovações, n. 5.

BRITO, A. N. de. O regime de progressão continuada e a formação de professores: um estudo sobre as iniciativas da Secretaria do Estado de São Paulo (1996-1998). 2001. Dissertação (Mestrado)- Pontifícia Universidade Católica-SP, São Paulo, 2001.

CORTELLA, M. S. A reconstrução da escola: a educação municipal em São Paulo de 1989 a 1991. Em Aberto, Brasília, ano 11, n. 53, p. 54-63, jan./mar. 1992.

CRUZ, S. H. V. O ciclo básico construído pela escola. 1994. Tese (Doutorado)- Faculdade de Educação, Universidade de São Paulo, São Paulo,1994.

DALBEN, Â. I.; FREITAS, L. de Avaliação escolar. um processo de reflexão da prática docente e da formação do professor no trabalho. 1998. Tese (Doutorado)- Faculdade de Educação, Universidade Federal de Minas Gerais, Belo Horizonte, 1998. $2000 \mathrm{a}$

. (Coord.) Avaliação da implementação do projeto político-pedagógico Escola Plural. Belo Horizonte: UFMG/FaE/Game, (Org.) Singular ou plural? Eis a escola em questão. Belo Horizonte: UFMG/ FaE/Game, 2000b. 
DAVIS, C.; ESPÓSITO, Y. L. A escola pública: um estudo sobre a aprendizagem nas séries iniciais. Estudos em Avaliação Educacional. São Paulo, n. 5, p. 29-50, jan./jun. 1992.

DURAN, M. C. G. 0 desafio de construir uma alfabetização de melhor qualidade: a proposta do ciclo básico em São Paulo. Tecnologia Educacional, Rio de Janeiro, v. 19, n. 95/96, p. 19-24, jul./out. 1990.

. Alfabetização na rede pública de São Paulo: a história de caminhos e descaminhos do ciclo básico. 1995. Tese (Doutorado)- Pontifícia Universidade Católica-SP, São Paulo, 1995.

DUTRA, A. H.; PEREIRA, L. A.; AURAS, M. A questão do avanço progressivo na educação catarinense. Cadernos do CED, Florianópolis, v. 1, n. 1/2, p. 13-110, 1984.

FERNANDES, C. A escolaridade em ciclos no Brasil: uma transição para a escola do século XXI. 2003. Tese (Doutorado)- Programa de Pós-graduação em Educação, Pontifícia Universidade Católica-RJ, Rio de Janeiro, 2003.

Promoção automática na década de 1950: uma revisão bibliográfica na RBEP. Revista Brasileira de Estudos Pedagógicos, Brasília, v. 81, n. 197, p. 76-88, jan./ abr. 2000.

FERNANDES, C.; FRANCO, C. Séries ou ciclos: o que acontece quando os professores escolhem? In: FRANCO, C. (Org.). Avaliação, ciclos e promoção na educação. Porto Alegre: Artmed Editora, 2001. p. 55-68.

FERRÃO, M. E.; BELTRÃO, K. I.; SANTOS, D. P. dos. Impacto das políticas de não-repetência no desempenho acadêmico dos alunos da $4^{a}$ série: modelagem multinível. Rio de Janeiro, 2002 (Relatório de Pesquisa).

FORTES, M. de F. A. A Escola Plural: uma nova concepção do processo ensino-aprendizagem. Presença Pedagógica, Belo Horizonte, v. 3, n. 13, p. 17-29, jan./fev. 1997.

FRANCO, C. Ciclos e letramento na fase inicial do ensino fundamental. In: REUNIÃO ANUAL DA ANPED, 26., 2003, Poços de Caldas. Trabalho apresentado... Poços de Caldas, 2003.

FREHESE, E. Democratização em xeque? Vicissitudes da progressão continuada no ensino paulista em 1999. 2001. Dissertação (Mestrado)- Faculdade de Educação, Universidade de São Paulo, São Paulo, 2001.

FREITAS, E. J. L. de. A implementação da política pública Escola Plural: as representações sociais dos pais sobre seus princípios de avaliação. 2000a. Disertação (Mestrado)- Universidade Federal de Minas Gerais, Belo Horizonte, 2000a.

FREITAS, J. C. de. Cultura e currículo: uma relação negada na política do sistema de progressão continuada no Estado de São Paulo. 2000b. Tese (Doutorado)- Pontifícia Universidade Católica-SP, São Paulo, 2000b.

FUSARI, J. C. et al. As reformas educacionais: com a palavra os professores. Revista de Educação, São Paulo, n. 13, p. 15-29, abr. 2001a.

. Reformas da Secretaria de Educação do Estado de São Paulo: considerações críticas. Revista de Educação, São Paulo, n. 13, p. 4-14, abr. 2001b.

GIUSTA, A. da S.; EUCLIDES, M. A. M.; RAMÓN, D. A. de M. Ciclos de formação na Escola Plural. Presença Pedagógica, Belo Horizonte, v. 5, n. 28, p. 17-27, jul./ago. 1999.

GUIMARÃES, M. N. do N. Práticas pedagógicas em época de progressão continuada: um olhar sobre a avaliação. 2001. Dissertação (Mestrado)- Universidade Federal de São Carlos, São Carlos, 2001.

JACOMINI, M. A. Uma década de organização do ensino em ciclos na rede municipal de São Paulo: um olhar dos educadores. 2002. Dissertação (Mestrado)- Faculdade de Educação, Universidade de São Paulo. São Paulo, 2002.

JEFFREY, D. C. Humanização e qualidade de ensino: uma estratégia (de) política educacional para educar o cidadão. 2001. Dissertação (Mestrado)- Faculdade de Educação, Universidade de Campinas, Campinas, 2001.

KRUG, A. Ciclos de formação: uma proposta transformadora. Porto Alegre: Editora Mediação, 2001. 
LEITE, M. I. P. de A. Méritos e pecados do ciclo no ensino fundamental: análise da implantação do ciclo de aprendizagem nas escolas da rede municipal de Vitória da Conquista. 1999. Dissertação (Mestrado)- Pontifícia Universidade Católica-SP, São Paulo, 1999.

MAGALHÃES, C. R. Políticas públicas e sala de aula: avaliando a transição de paradigmas. 1999. Dissertação (Mestrado)Universidade Federal de São Carlos, São Carlos, 1999.

MAINARDES, J. Ciclo básico de alfabetização: da intenção à realidade (avaliação do CBA no município de Ponta Grossa- PR). $1995 \mathrm{a}$. Dissertação (Mestrado)- Faculdade de Educação, Universidade de Campinas, Campinas, 1995a.

. Ciclo básico de alfabetização: da intenção à realidade (Avaliação do CBA no município de Ponta Grossa - PR). Trajetos, Campinas, n. 6, p. 39-51, dez. 1995b.

. A organização da escolaridade em ciclos: ainda um desafio para os sistemas de ensino. In: FRANCO, C. (Org.). Avaliação, ciclos e promoção na educação. Porto Alegre: Artmed Editora, 2001. p. 35-54.

. A promoção automática em questão: argumentos, implicações e possibilidades. Revista Brasileira de Estudos Pedagógicos, Brasília, v. 79, n. 192, p. 16-29, maio/ago. 1998.

NEGRI, S. M. A. M. Ciclo básico de alfabetização: os limites de um projeto político. 1994. Dissertação (Mestrado)- Universidade Metodista de Piracicaba, Piracicaba, 1994.

NEUBAUER, R. Quem tem medo da progressão continuada? Ou melhor, a quem interessa o sistema de reprovação e exclusão social? Acesso, São Paulo, n. 14, p. 11-18, dez. 2000.

NEUBAUER, R.; DAVIS, C.; ESPÓSITO, Y. L. Avaliação do processo de inovações no ciclo básico e seu impacto sobre a situação de ensino-aprendizagem na região metropolitana de São Paulo. Estudos em Avaliação Educacional, São Paulo, n. 13, p. 35-64, jan./ jun. 1996.

NUNES, J. B. C. O impacto da política educacional sobre a socialização profissional docente: elementos para se repensar as reformas na educação. In: CONGRESSO LUSO-BRASILEIRO DE POLITICA E ADMINISTRAÇÃO DA EDUCAÇÃO, 2001, Braga. Comunicação... Braga: Universidade do Minho, 2001.

PALMA FILHO, J. C. A reforma curricular da secretaria da educação do estado de São Paulo para o ensino de $1^{\circ}$ grau (1983-1987): uma avaliação crítica. 1989. Dissertação (Mestrado)- Programa de Educação: Supervisão e Currículo. Pontifícia Universidade Católica-SP, São Paulo, 1989.

PALMA FILHO, J. C.; ALVES, M. L.; DURAN, M. C. G. Ciclo básico em São Paulo: memórias da educação nos anos 1980. São Paulo: Xamã, 2003.

PARO, V. Reprovação escolar: renúncia à educação. São Paulo: Xamã, 2001.

PEREIRA, L. R. Ampliação do período de alfabetização nas séries iniciais: a experiência de Minas Gerais. Idéias, São Paulo, n. 1, p. 56-61, 1988.

PORTO ALEGRE, Secretaria Municipal de Educação. Ciclos de formação: proposta político-pedagógica da Escola Cidadã. Cadernos Pedagógicos. Porto Alegre, n. 9, maio 2003.

Turmas de progressão: a inversão da lógica da exclusão. Porto Alegre: SMED, 1999.

RENAZZO, A. A. Alunos do ciclo básico com dificuldade de aprendizagem: um programa de treinamento para estagiários de habilitação específica de $2^{\circ}$ grau para o magistério. 1987. Dissertação (Mestrado)- Pontifícia Universidade Católica-SP, São Paulo, 1987.

SÃO PAULO (Município) Secretaria de Educação. Cidade educadora - educação inclusiva: um sonho possível. São Paulo: SME/ DOTG./, 2003 (EducAção 4).

SENA, G. O. de; MEDEIROS, N. R. L. 0 sistema de avanço progressivo e suas conseqüências no estado de Santa Catarina. Cadernos CED, Florianópolis, ano 1, n. 1/2, p. 111-174, 1984. Número especial. 
SILVA, M. S. P. da; MELLO, F. C. M. de. Políticas para enfrentamento do fracasso escolar. uma análise da proposta Escola Plural de Belo Horizonte. In: REUNIÃO ANUAL DA ANPED, 24., 2001, Caxambu, MG. Anais eletrônicos... Caxambu, MG, 2001. Disponível em: <www.anped.org.br/24/P0568099736774.doc>.

SILVA, R. N. da; DAVIS, C. É proibido repetir. Estudos em Avaliação Educacional, São Paulo, n. 7, p. 5-44, jan./jun. 1993.

SILVA, Z. I. F. da. Ciclo básico de alfabetização nas escolas estaduais da cidade de São Paulo: um estudo em 4 escolas. 1990. Dissertação (Mestrado)- Pontifícia Universidade Católica-SP, São Paulo, 1990.

. Um estudo avaliativo sobre o Ciclo Básico de alfabetização em quatro escolas de São Paulo. Estudos em Avaliação Educacional, São Paulo, n. 3, p. 49-69, jan./jun. 1991.

SOARES, C. C. Construindo a Escola Plural: a apropriação da Escola Plural por docentes do $3^{\circ}$ ciclo do ensino fundamental. 2000. Dissertação (Mestrado)- Universidade Federal de Minas Gerais, Belo Horizonte, 2000.

SOUSA, S. Z. L. de; ALAVARSE, O. M. A avaliação nos ciclos: a centralidade da avaliação. In: FREITAS, L. C. de; GATTI, B. A.; SOUSA, S. M. Z. L. (Org.). Questões de avaliação educacional. Campinas, SP: Komedi, 2003. p. 71-96. (Série Avaliação: construindo o campo e a crítica)

SOUSA, S. Z. L. de et al. Ciclos e progressão escolar: indicações bibliográficas. Ensaio, Rio de Janeiro, v. 11, n. 38, p. 99-114, jan./mar. 2003.

SOUZA, M. G. de. Educação e diversidade cultural: uma análise da proposta da Escola Plural do Município de Belo Horizonte. 2000. Dissertação (Mestrado)- Programa de Educação, Pontifícia Universidade Católica-RJ, Rio de Janeiro, 2000.

STEINVASHER, A. A implantação da progressão continuada no Estado de São Paulo: um caminho para a democratização do ensino? 2003. Dissertação (Mestrado)- Faculdade de Educação, Universidade de São Paulo, São Paulo, 2003.

VIANNA, H. M. Avaliação do ciclo de alfabetização em Minas Gerais. Estudos em Avaliação Educacional, São Paulo, n. 5, p. 49-69, jan./jun. 1992a.

Desempenho dos alunos do CBA em Minas Gerais: análise dos resultados e identificação de pontos críticos. Estudos em Avaliação Educacional, São Paulo, n. 6, p. 61-94, jul./dez. 1992b.

VIANNA, H. M; SQUÁRCIO, N. do C.; VILHENA, M. G. C. de. As escolas estaduais de Minas Gerais e o CBA. Estudos em Avaliação Educacional, São Paulo, n. 6, p. 137-159, jul./dez. 1992.

VIEGAS, L. de S. Progressão continuada e suas repercussões na escola pública: concepções de educadores. 2002. Dissertação (Mestrado)- Instituto de Psicologia, Universidade de São Paulo, São Paulo, 2002.

ZAIDAN, S. Ciclos no ensino fundamental: um projeto de inclusão? Presença Pedagógica, Belo Horizonte, v. 5, n. 30, p. 49-59, nov./ dez. 1999.

Recebido em 09.03.04

Aprovado em 14.04.04

Elba Siqueira de Sá Barretto é professora da Faculdade de Educação da Universidade de São Paulo, Departamento de Metodologia do Ensino e Educação Comparada; pesquisadora da Fundação Carlos Chagas, editora de Cadernos de Pesquisa, periódico científico da área de educação.

Sandra Zákia Sousa é professora da Faculdade de Educação da Universidade de São Paulo, Departamento de Administração Escolar e Economia da Educação. 